\title{
Knowledge Regarding Diabetes Mellitus among Rural People in a Selected Area of Bangladesh
}

\author{
K S Imtiaz ${ }^{1}$, M Chowdhury ${ }^{2}$, H Nazneen ${ }^{3}$, N Begum ${ }^{4}$, N Tamanna ${ }^{5}$, F Alam ${ }^{6}$, M J Akter ${ }^{7}$
}

${ }^{1}$ Dr. Khondker Saif Imtiaz MBBS, MPH, DPS, PGDDM Associate Professor \& Head, Dept. of Community Medicine CARe Medical College,Dhaka

${ }^{2}$ Prof. Dr. Mahmuda Chowdhury MBBS, MPH, DMEd, MMEd Professor \& Head

${ }^{3}$ Dr. Humaira Nazneen MBBS, MPH

Associate Professor

${ }^{4}$ Dr. Nasreen Begum MBBS, MPH

Assistant Professor Dept. of Community Medicine Northern International Medical College

Dr. Nushrat Tamanna MBBS, MPH

Assistant Professor

Pr. Fardous Alam

MBBS, MPH, CCD

Assistant Professor

${ }^{7}$ Mst. Jesmin Akter

BSN, MPH

Instructor

Ad-din Nursing College, Dhaka

$2,3,5,6$

Dept. of Community Medicine International Medical College

Correspondence

Dr. Khondker Saif Imtiaz

Associate Professor \& Head

Dept. of Community Medicine

CARe Medical College, Dhaka

E-mail: saifimtiaz105@yahoo.com

\section{Abstract}

Background: Diabetes mellitus (DM) is one of the major public health concerns throughout the world. In 2013, there were 382 million people living with DM, and this number is projected to increase to 471 million by 2035. It affects large number of people of wide range of ethnic and economic levels in both developed and developing countries.

Objective : The study was undertaken to assess the knowledge regarding diabetes mellitus among rural people in a selected area of Bangladesh.

Methods : A descriptive type of cross sectional study was conducted from November 2015 to January 2016 among 400 people of a village of Gazipur district. The data were collected by using pre tested, semi-structured, interviewer administered questionnaire. Non probability purposive sampling technique was followed. Knowledge related variable were initial symptoms, curability, prevention, risk factors, complications, changes occur inside the body, perceived causes and investigation of DM. Data analysis was done by statistical software, SPSS version 20.

Results : Out of 400 respondents, majority (47.50\%) were in the age group of 21.30 years. Most $(58.25 \%)$ of them were male and in terms of educational status $80.5 \%$ respondents were literate having varying levels of education. Majority $(48.75 \%)$ of respondents were service holder. Nearly all of respondents (92\%) heard about DM and their source of information was from neighbour $28.89 \%$ followed by health care provider $27.71 \%$. Majority of respondents had good knowledge regarding initial symptoms $53.80 \%$ and curability $60.86 \%$ of DM. Most of them had fair knowledge regarding prevention $35.86 \%$ and risk factors $48.09 \%$ of DM. Majority $70.92 \%$ respondents had poor knowledge regarding complications of diabetes mellitus. Most respondents had no knowledge regarding changes occur inside the body $75.27 \%$, perceived causes of DM 61.69\% and investigation $61.41 \%$ of DM.

Conclusion : This study concluded that good knowledge was found on initial symptom and curability of Diabetes mellitus, fair knowledge on risk factor and prevention and poor knowledge was found regarding complications of DM. No knowledge was found regarding changes occur inside the body, perceived causes and investigation of Diabetes mellitus. Therefore, effective awareness and health education program to the rural people regarding various aspects of Diabetes mellitus are in urgent need.

Key wards : Diabetes Mellitus, Knowledge, Rural people.

Northern International Medical College Journal Vol. 7 No. 02 January 2016, Page 131-134

\section{Introduction}

Diabetes mellitus consists an enormous public health problem globally, associated with high morbidity and mortality. It is a group of metabolic disorders characterized by chronic hyperglycemia with disturbance of carbohydrate, fat and protein metabolism, resulting from a diversity of etiologies. Diabetes mellitus is due to either the pancreas not producing enough insulin or the cells of the body not responding properly to the insulin produced. ${ }^{1}$ If left untreated, diabetes mellitus can cause many complications of which acute complications include diabetic ketoacidosis and nonketotic hyperosmolar coma ${ }^{2}$ and serious long-term complications include cardiovascular disease, stroke, chronic kidney failure, foot ulcers, and damage to the eyes. ${ }^{3}$

Diabetes mellitus is an emerging threat to the world's health service. Although increase in both the prevalence and incidence of type 2 diabetes have occurred globally, they have been especially dramatic in societies in economic transition, in newly industrialized countries and in developing countries. ${ }^{4}$ As of 2014, an estimated 387 million people have diabetes mellitus worldwide, ${ }^{5}$ with type 2 diabetes mellitus making up about $90 \%$ of the cases. This represents $8.3 \%$ of the adult population, ${ }^{6}$ with equal rates in both women and men. From 2012 
to 2014 , diabetes mellitus is estimated to have resulted in 1.5 to 4.9 million deaths each year. ${ }^{7}$ The global economic cost of diabetes mellitus in 2014 was estimated to be $\$ 612$ billion USD. 8

Diabetes mellitus also common in Bangladesh. At present it is estimated that about 3.6 million people are affected throughout the country. The overall estimated prevalence of diabetes mellitus in Bangladeshi population is $5.6 \%$, in which more than $96 \%$ is reported to have type 2 diabetes mellitus and higher prevalence is found in urban areas predominantly among women. If the trend continues to grow in Bangladeshi population where the growth rate is $1.8 \%$ and in approximately 160 million people, the problem of Diabetes mellitus as a major health issue should certainly alarm the health planners of the country ${ }^{8}$.

Methods : A descriptive type of cross sectional study was conducted from November 2015 to January 2016. After taking concent data were collected by self administered questionnaire from 400 rural people of Gazariapara village of Gazipur district. Purposive sampling technique was followed in selecting sample. Collected data were verified in order to reduce the errors and inconsistencies. Data analysis has been performed with the aid of advance statistical analysis software, SPSS version 20.

Questions regarding various aspects of Diabetes Mellitus were incorporated in the questionnaire e.g initial symptoms, risk factors, curability, investigation, complications, prevention, perceived causes and changes occur inside the body. Knowledge level has been operationalized into good, fair, poor and no knowledge. In case of questions having multiple correct answers, those who had given three or more correct answers were considered as having good knowledge, who had given two correct answers were considered as having fair knowledge, who had given one correct answer were considered as having poor knowledge and who had given incorrect answers were considered as having no knowledge. In case of single correct answer questions, those who had given the correct answer were considered as having good knowledge and who had given the incorrect answer were considered as having no knowledge.

Results : Among 400 respondents, majority (47.50\%) were 2130 years of age and least were $<20$ years of age. According to sex, most $(58.25 \%)$ of the respondents were male. Regarding education, majority (80.50\%) were educated in different level. Only $19.50 \%$ of them were illiterate. In case of occupation, majority $(48.75 \%)$ of the respondents were service holder, followed by business (17.50\%), daily worker $(13.00 \%)$ and farmer $(11.25 \%)$. Regarding income, majority $(33.75 \%)$ of the respondent's monthly family income was $10,000-15,000$ Tk. (table-I)
Table I : Socio demographic characteristics of the respondents $(n=400)$

$\begin{array}{ccc}\text { Age in years } & \text { Frequency } & \text { Percentage (\%) } \\ <20 & 24 & 6.0 \\ 21-30 & 190 & 47.50 \\ 31-40 & 97 & 24.25 \\ >40 & 89 & 22.25 \\ \text { Sex } & & \\ \text { Male } & 233 & 58.25 \\ \text { Female } & 167 & 41.75\end{array}$

\section{Educational status}

$\begin{array}{ccc}\text { Illiterate } & 78 & 19.50 \\ \text { Primary } & 126 & 31.50 \\ \text { Secondary } & 154 & 38.50 \\ \text { Higher Secondary } & 31 & 7.75 \\ \text { Graduate } & 11 & 2.75\end{array}$

\section{Occupation}

$\begin{array}{ccc}\text { Farmer } & 45 & 11.25 \\ \text { Service holder } & 195 & 48.75 \\ \text { Business } & 70 & 17.50 \\ \text { Daily worker } & 52 & 13.00 \\ \text { Jobless } & 38 & 9.50\end{array}$

Monthly family income

$\begin{array}{ccc}<5,000 & 30 & 7.5 \\ 5,000-10,000 & 107 & 26.75 \\ 10,000-15,000 & 135 & 33.75 \\ 15,000-20,000 & 63 & 15.75 \\ >20,000 & 65 & 16.25\end{array}$

Regarding Diabetes Mellitus 368 (92\%) of the respondents have heard about Diabetes mellitus, whether $32(8 \%)$ have not heard regarding this subject. (Figure-1)

\section{Figure-1: Distribution of respondents according to whether they} have ever heard regarding Diabetes mellitus $(n=400)$

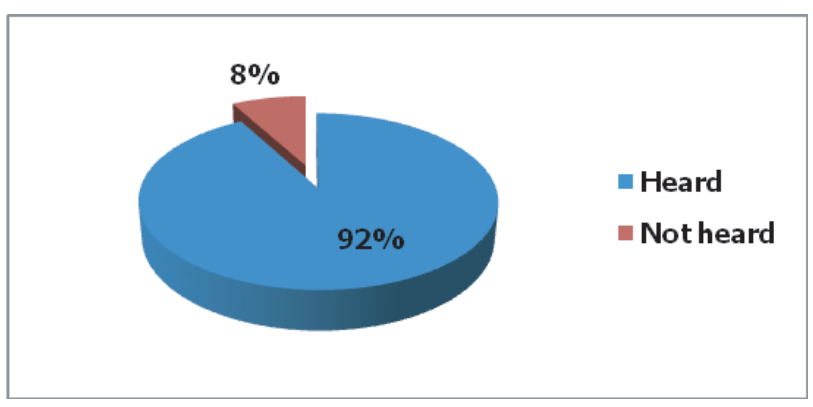

Majority (28.82\%) of the respondents have heard information regarding Diabetes mellitus, from neighbor followed by health care provider $(27.71 \%)$, friends and relatives $(25.27 \%)$ and television and radio (14.40\%) figure-2, 
Figure-2 : Distribution of respondents according to their source of information about DM regarding Diabetes mellitus $(n=368)$

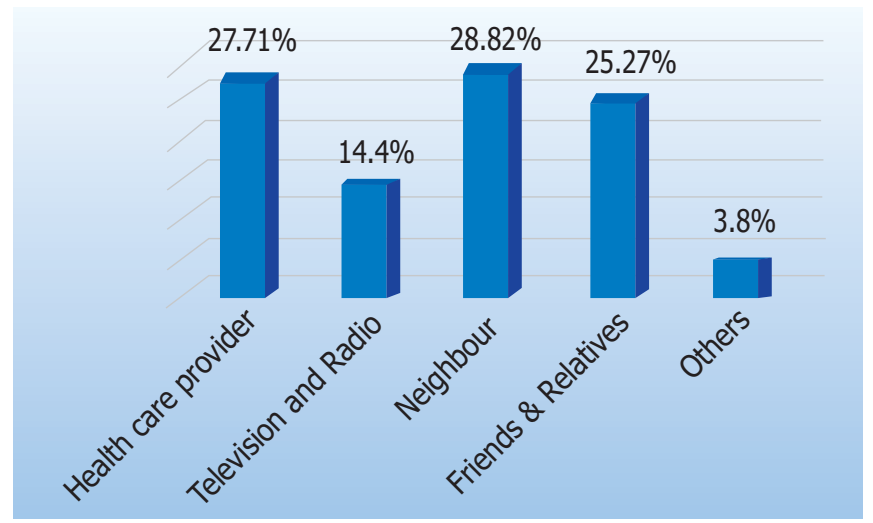

Level of knowledge regarding various aspects of DM, most of them $(75.27 \%)$ had no knowledge and only $(24.73 \%)$ had good knowledge regarding changes occur inside the body in diabetes mellitus. In case of perceived causes of DM, majority (61.69\%) had no knowledge and only $18.75 \%$ had good knowledge. Regarding risk factors of diabetes mellitus, $48.09 \%$ had fair knowledge $17.93 \%$ had no knowledge and only $12.5 \%$ had good knowledge. Most $(60.86 \%)$ of the respondents had good knowledge and (39.14\%) had no knowledge about curability of DM. Regarding initial symptoms of diabetes mellitus, majority $(53.8 \%)$ of the respondents had good knowledge. In case of complications of DM, majority (70.92\%) had poor knowledge followed by $13.31 \%$ no knowledge and only $6.25 \%$ had good knowledge. Most $(61.41 \%)$ of the respondents had no knowledge and the rest (38.59\%) had good knowledge about investigations of DM. Regarding prevention of DM, majority (35.86\%) of respondents had fair knowledge. (table II)

\section{Discussion}

This descriptive type of cross sectional study was conducted among 400 people to assess the knowledge regarding diabetes mellitus among them. Among the respondents, was majority $(47.50 \%)$ were $21-30$ years of age followed by $(24.25 \%)$ were $31-40$ years, $(22.25 \%)$ were $>40$ years. Age distribution was similar with the study in India by Poornima $\mathrm{S}$ et $\mathrm{al}^{10}$. According to sex, most $(58.25 \%)$ of the respondents were male and the rest $(41.75 \%)$ were female. Similar sex distribution was found in a study by Varshil Mehta ${ }^{11}$ Regarding education, majority of the respondent's educational level belongs to secondary (38.50\%) and primary $(31.50 \%)$ followed by higher secondary $(7.75 \%)$ \& graduate $(2.75 \%)$ and $19.50 \%$ of them were illiterate. These finding were consistent with the study conducted by Sueziani Binte Zainudin et al in Singapore ${ }^{12}$. In this study, majority of the respondents belonged to sedentary worker and from low middle class.

Majority (92\%) of the respondents have heard regarding Diabetes mellitus, whether $8 \%$ have not heard regarding this subject. A study conducted by Mohan $D$ et $\mathrm{al}^{13}$ suggested that $75.5 \%$ of the respondents of Chennai, India had heard regarding Diabetes mellitus. Most (28.82\%) of the respondents have heard information regarding Diabetes mellitus, form neighbor followed by health care provider $(27.71 \%)$, friends and relatives $(25.27 \%)$ and television and radio (14.40\%). Therefore, health care providers and the audio visual media should provide more emphasis to disseminate information about DM to the rural people.

Regarding changes occur inside the body in DM, most of them $(75.27 \%)$ had no knowledge and only $24.73 \%$ had good knowledge. On asking perceived causes of diabetes mellitus, majority $(61.69 \%)$ had no knowledge, Regarding risk factors of

Table-II : Distribution of respondents according to level of knowledge regarding various aspects of Diabetes mellitus $(n=368)$

\begin{tabular}{|c|c|c|c|c|c|c|c|c|}
\hline \multirow{2}{*}{$\begin{array}{c}\text { Knowledge related } \\
\text { variables }\end{array}$} & \multicolumn{7}{|c|}{ Level of Knowledge } \\
\cline { 2 - 10 } & \multicolumn{2}{|c|}{ Good Knowledge } & \multicolumn{2}{|c|}{ Fair Knowledge } & \multicolumn{2}{c|}{ Poor Knowledge } & \multicolumn{2}{c|}{ No Knowledge } \\
\cline { 2 - 10 } & Frequency & $\%$ & Frequency & $\%$ & Frequency & $\%$ & Frequency & $\%$ \\
\hline $\begin{array}{c}\text { Changes occur in side } \\
\text { the body }\end{array}$ & 91 & 24.73 & - & - & - & - & 277 & 75.27 \\
\hline Perceived causes & 69 & 18.75 & 50 & 13.59 & 22 & 5.97 & 227 & 61.69 \\
\hline Risk factors & 46 & 12.5 & 177 & 48.09 & 79 & 21.48 & 66 & 17.93 \\
\hline Curability & 224 & 60.86 & - & - & - & - & 144 & 39.14 \\
\hline $\begin{array}{c}\text { Initial symptoms } \\
\text { Complications }\end{array}$ & 198 & 53.8 & 93 & 25.28 & 34 & 9.24 & 43 & 11.68 \\
\hline Investigation & 142 & 38.59 & - & - & - & - & 226 & 61.41 \\
\hline Prevention & 68 & 18.48 & 132 & 35.86 & 93 & 25.27 & 75 & 20.39 \\
\hline
\end{tabular}


diabetes mellitus, majority $(48.09 \%)$ had fair knowledge followed by $17.93 \%$ had no knowledge and only $12.5 \%$ had good knowledge. A study conducted by Munninarayana C. et al ${ }^{14}$ suggested that $45 \%$ of the participants had good knowledge about risk factors of DM.

Most $(60.86 \%)$ of the respondents had good knowledge and $39.14 \%$ had no knowledge about curability of DM. Regarding initial symptoms of diabetes mellitus, majority $(53.8 \%)$ of the respondents had good knowledge. In case of complications of diabetes mellitus, majority $(70.92 \%)$ had poor knowledge. Most $(61.41 \%)$ of the respondents had no knowledge and the rest (38.59\%) had good knowledge about investigation of diabetes mellitus. Regarding prevention of diabetes mellitus, majority $(35.86 \%)$ of respondents had fair knowledge. Therefore, a large portion of people had lack of good knowledge regarding investigations and preventive aspects of the disease.

\section{Conclusion}

The rural people in study area had good knowledge on controllability and initial symptom of DM and no knowledge on changes occur inside the body in diabetic patients and also regarding investigations of DM. They had fair knowledge on risk factor and prevention and poor knowledge was found about the complications of DM. Therefore, health education program, mass media campaign, diabetic camp could be organized to increase awareness on DM for the rural people.

\section{References}

1. Shoback, edited by David G. Gardner, Dolores (2011). "Chapter 17".Greenspan's basic \& clinical endocrinology (9th ed.). New York: McGraw-Hill Medical

2. Kitabchi, AE; Umpierrez, GE; Miles, JM; Fisher, JN (Jul 2009). "Hyperglycemic crises in adult patients with diabetes.". Diabetes Care 32 (7): 1335-43

3. Diabetes Fact sheet №312". WHO. October 2013. Retrieved 25 March 2014

4. Park K. Epidemiology of Chronic Non-communicable Diseases and Condition. Park's Textbook of Preventive and social Medicine, Jabalpur, M/S Banarsidas Bhanot Publishers, 23 ${ }^{\text {rd }}$ Edition 2015, Page 393

5. "Update 2014". IDF. International Diabetes Federation. Retrieved 29 November 2014

6. Shi,Yuankai; Hu, Frank B (7 June 2014). "The global implications of diabetes and cancer". The Lancet 383 (9933): 1947-8

7. "The top 10 causes of death Fact sheet $N^{\circ} 310 "$. World Health Organization. Oct 2013

8. IDF DIABETES ATLAS (PDF) (6th Ed.). International Diabetes Federation. 2013. p. 7

9. Statistics from Diabetic Association of Bangladesh (DAB). Retrieved from http://www.diabetes-bd.org/diabetesin bangladesh.htr

10. Poornima S1, Ragavendra L2, Shivakumar KM; AWARENESS REGARDING DIABETES MELLITUS AMONG DEGREE COLLEGE STUDENTS OF MANDYA CITY, KARNATAKA, INDIA Indian J. Prev. Soc. Med. 2012, 43(3):10-13

11. Varshil Mehta, Assessment of Knowledge, Attitude and Awareness of Diabetes Mellitus in adults of a slum area of Mumbai, India: A Cross-Sectional Study. Indian Journal of Applied Research; 2015, 5 (12): 15-18

12. Sueziani Binte Zainudin, Dun Yong Ang, Abel Wah Ek Soh, Knowledge of diabetes mellitus and safe practices during Ramadan fasting among Muslim patients with diabetes mellitus in Singapore; Singapore Med J 2016, 1-20 doi: 10.11622/smedj.2016085 Published ahead of print: 28 April 2016

13. Mohan D, Raj D. Awareness and knowledge of Diabetes in Chennai - The Chennai Urban and rural Epidemiology Study. J Assoc. Physicians India.2005; 53: 283-7

14. Munninarayana C, Balchandra G,et al. Prevalence and awareness regarding diabetes mellitus in rural Tomaka, Korala. Ind J Diab.2000; 30 (01):18-19 